\title{
Effect of Strategic Management on the Development of Entrepreneurial Competency in Nigeria
}

\author{
Umar Abbas Ibrahim, PhD* \\ Department of Business Administration, Nile University of Nigeria, Nigeria \\ Frank Oli \\ Department of Business Administration, Nile University of Nigeria, Nigeria
}

\begin{abstract}
This article determined the effect that strategic management has on the development of entrepreneurial competence in Nigeria. It also examined the influence of strategic management on competitive advantage, development and advancement of entrepreneurial competencies in Organizations. This study made use of survey research design. The population consists of forty (40) managers of small and medium sized enterprises operating in Abuja Nigeria. Simple random sampling techniques was employed. The study made use of primary source of data through distribution of questionnaire, using a five-point likert scale. Pearson Product Moment Correlation was used to test hypotheses, with the help of Statistical Package for Social Sciences (SPSS 20.1). In conclusion, the strategic management of an organization therefore can result in the positive advancement of entrepreneurial competencies if is appropriately implemented. Organizations that witnessed a positive implication of strategic management on the development and advancement of entrepreneurial competence are those who offered training centered on the acquisition of entrepreneurial competencies. The results showed that strategic management significantly enhance competitive advantage, there is significant relationship between strategic management and development of entrepreneurial competencies in Nigeria and strategic management significantly enhance advancement of entrepreneurial competencies in Organizations. The study therefore recommended amongst others that organizations should invest in training of their employees, as the human resource is an important internal strength of every organization and are therefore a source of competitive advantage for the firm and organizations should involve professional in their strategic management processes to increase the level of development and advancement of entrepreneurial competencies in Organizations.
\end{abstract}

Keywords: Strategic Management, Entrepreneurial Competence, Entrepreneurship.

DOI: $10.7176 / \mathrm{EJBM} / 12-3-21$

Publication date: January $31^{\text {st }} 2020$

\section{Introduction}

Entrepreneurial competency is crucial to the success of every organizations in competitive and fast shifting business environments. Organizations should gain and develop their competencies in entrepreneurship so as to acquire a competitive advantage. In addition, strategic management of an organization ensures the attainment of organizational goals. Strategic management deals with the formulation and implementation of organizational goals and as such innovation and staying ahead of the competition is an important aspect. Entrepreneurial competence within an organization is important in innovating and attaining organizational goals (14).

According to (17) strategic management and entrepreneurship are linked to the performance and behavior of business. Strategic management aims to establish and develop competitive advantages for organizations. Entrepreneurship promotes the exploration of competitive advantage through introducing products, innovations and processes into the market. Strategic management and entrepreneurship therefore play a crucial role in increasing profits and the strategic competitive position of the organization.

Strategic management and entrepreneurship are closely related to the decision-making capabilities of managers. Strategic management greatly enhance the results of the organizations such as advantages, funds sustainable competitive and strategy. Entrepreneurship is focused on growth and innovation whereas strategic management is focused on competitive advantages (27). Combining entrepreneurship and strategic management results in wealth creation for the firm and therefore facilitating the success of the organization.

According to (11) the success of a company is closely related to its strategic management and therefore the goals of the organization should be aligned in a manner that promotes its success. In the current business environment, success can be achieved through innovation and innovation in turn gives a competitive advantage to the company. It is therefore important that strategic management of a company promotes entrepreneurship. This can be attained through the organization developing entrepreneurial competencies. It is therefore important to determine whether strategic management has an impact on the development of entrepreneurial competences (5) 
Every entrepreneur begins their venture with hopes of great competence, but nearly half of them breakdown within two years. Failure to innovate means that businesses are likely to incur losses which may result to organization's demise. Innovation in an organization can be developed through the promotion of entrepreneurship competency within the organizations. Many entrepreneurs lack innovative ideas to improve products or services. Government policies have fallen short of expectations (2), lack of entrepreneurial knowledge has characterized development of entrepreneurial competency in Nigeria which has resulted to poverty, unemployment, low gross domestic products and low standard of living of people in the country. In Nigeria our leaders have frequently come to their position with limited experience battled on, confronting their awesome problems of development and nation building, essentially unprepared and unaided on entrepreneurial development. In Nigeria, entrepreneurs lacked access to resources including credit and technology, electricity supply, water and good road network because of the deterioration of the economic situation since in the 1980's, till today. Some of the entrepreneurial related policies are good but the issue of poor environmental forces hinders them (12).

From the above studies the researcher observed that there is none of the authors that undertook a research work on the topic 'Effects of strategic management on the development of entrepreneurial competency in Nigeria" therefore, the researcher was interested in the study in order to bridge the observed gap.

The main objective of this study is to determine the effects of strategic management on the development of entrepreneurial competency in Nigeria. The specific objectives are to:

$i$. Determine whether strategic management enhances competitive advantage in Nigeria.

ii. Examine the extent to which strategic management affects development of entrepreneurial competencies in Nigeria.

iii. Determine the extent to which strategic management enhance in the advancement of entrepreneurial competencies in Organizations.

The study seeks to answer the following questions:

i. To what extent does strategic management enhance competitive advantage in Nigeria?

ii. Does strategic management affect development of entrepreneurial competencies in Nigeria?

iii. How does strategic management enhance in the advancement of entrepreneurial competencies in Organizations?

The hypotheses being assessed in this research are:

i. Strategic management does not significantly enhance competitive advantage in Nigeria.

ii. There is no significant relationship between strategic management and development of entrepreneurial competencies in Nigeria.

iii. Strategic management does not significantly enhance advancement of entrepreneurial competencies in Organizations.

\section{Literature review}

\subsection{Concept of Strategic Management}

Strategic management refers to the manner in which a firm plans to engage with various aspects of management such as issues of risk taking, uncertainty, innovation, substantial resources and divergent thinking (1). In other word, it is a means by which an organization establishes its goals and perceives the goals of the organization as being aligned with the firm's resources as well as constraints in the organization (26). Furthermore, strategic management entails the creation, implementation and evaluation of business strategies with the goal of attaining organizational objectives.

Strategic management is the idea that strategy establishes an association between the internal strengths and failings of a firm, as well as openings and threats in the firm's external environment. The main goals of strategic management are the formulation of goals, analysis of the business environment, as well as the creation, implementation, assessment and control of approaches (26). Profitability of companies in the same sector and knowledge of competitive organizational environment is determined through a SWOT analysis. This makes it possible for the organization to utilize its strengths, minimize its weaknesses, take advantage of opportunities that may arise and take measures to deal with threats to the business (Ismail, 2012).

Industrial organization as another perspective in strategic management which argues that external environment establishes the strategic actions to be deployed by an organization. Therefore, organizations should recognize and seek to function in an environment that allows activities that are strategic, which in turn create profitability and 
competitively (26).

Strategic management often takes place in two main phases: strategic evaluation and the planning of strategic activities. Strategic evaluation is undertaken through a SWOT analysis. An internal analysis of the resources of the firm is also undertaken.

The figure below explains the following component of strategic management:

Strategy Evaluation: Strategy evaluation is strategy management process. The key strategy evaluation activities are: appraising environmental internal and external factors that are the root of present strategies, measuring performance, and taking remedial / corrective actions. Evaluation makes sure that the organizational strategy as well as its implementation meets the organizational objectives. These components are steps that are carried, in chronological order, when creating a new strategic management plan.

Strategy Planning: strategic planning include the creation of a blueprint of the organization's acquisition, business level, competitive, corporate level, collaborative and acquisition strategies (26).

Strategy Implementation: Strategy implementation can be best explained as the process of putting the organizational approved strategy into action with clear emphasis on development of structure, allocation of resources and responsibilities and facilitating human capacity. (Akinyele \& Fasogbon, 2007).

Outcome of the strategic action after executing and evaluating the process, management should look at the outcome if it meets the expected results (Zhang 2009).

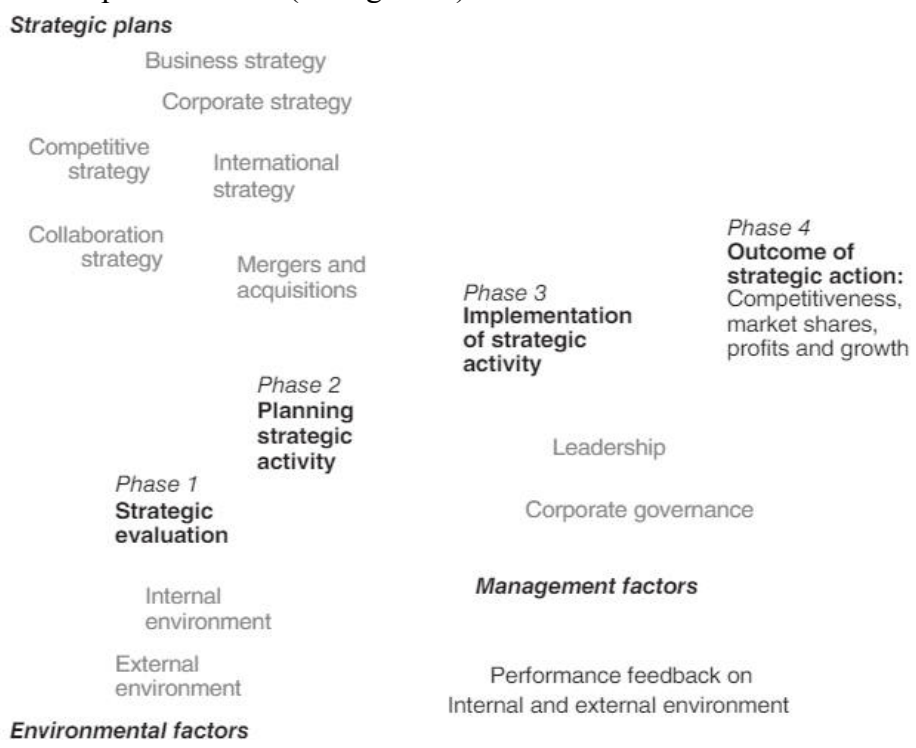

Fig 1: Components of strategic management

Source: (Hitt, Ireland \& Hoskisson 2012)

\subsection{Concept of entrepreneurial competencies}

Entrepreneurial Competence: The competency approach is a method of reviewing entrepreneurial characteristics (16). The scanning of environment, selection of possible opportunities and strategy formulation is ascribed to the classic entrepreneurial role (7). According to (14) entrepreneurial competencies are a set of higher level characteristics involving personality traits, skills and knowledge. They can be perceived the possibility of the entrepreneur to perform identified roles successfully (5). Further, (4) outlined 12 competency areas that are required for small business successful performance, and it includes: starting a business, planning and budgeting, management, marketing/selling, advertising and sale promotion, merchandizing, financing and accounting, personnel relations, purchasing, production, facilities and equipment, and controlling risk. Moreover, (18) notes that entrepreneurial competency is aggregated total of an entrepreneur's requisite attributes for successful and sustainable entrepreneurship, including attitudes, values, beliefs, knowledge, skills, abilities, personality, wisdom, expertise (social, technical, managerial), mindset and behavioral tendencies. (24) stresses that the entrepreneur 
requires key intelligence which involves a balance of analytical, creative and practice abilities to achieve desire goals.

(3). Presents a three -layered concept of entrepreneurship competencies and notes that proper entrepreneurial competencies are helpful when undertaking to start an enterprise and to help it survive or grow; furthermore, entrepreneurial competency is an integrated ability to perform entrepreneurial activities effectively. These comprise mainly; the ability to recognize and analyze market opportunities; the ability to communicate, identify mentally, persuade and discuss with all stakeholder in the business environment; and the ability to establish networks linking with businesspersons and stakeholders for mutual learning and collaboration undertaking.

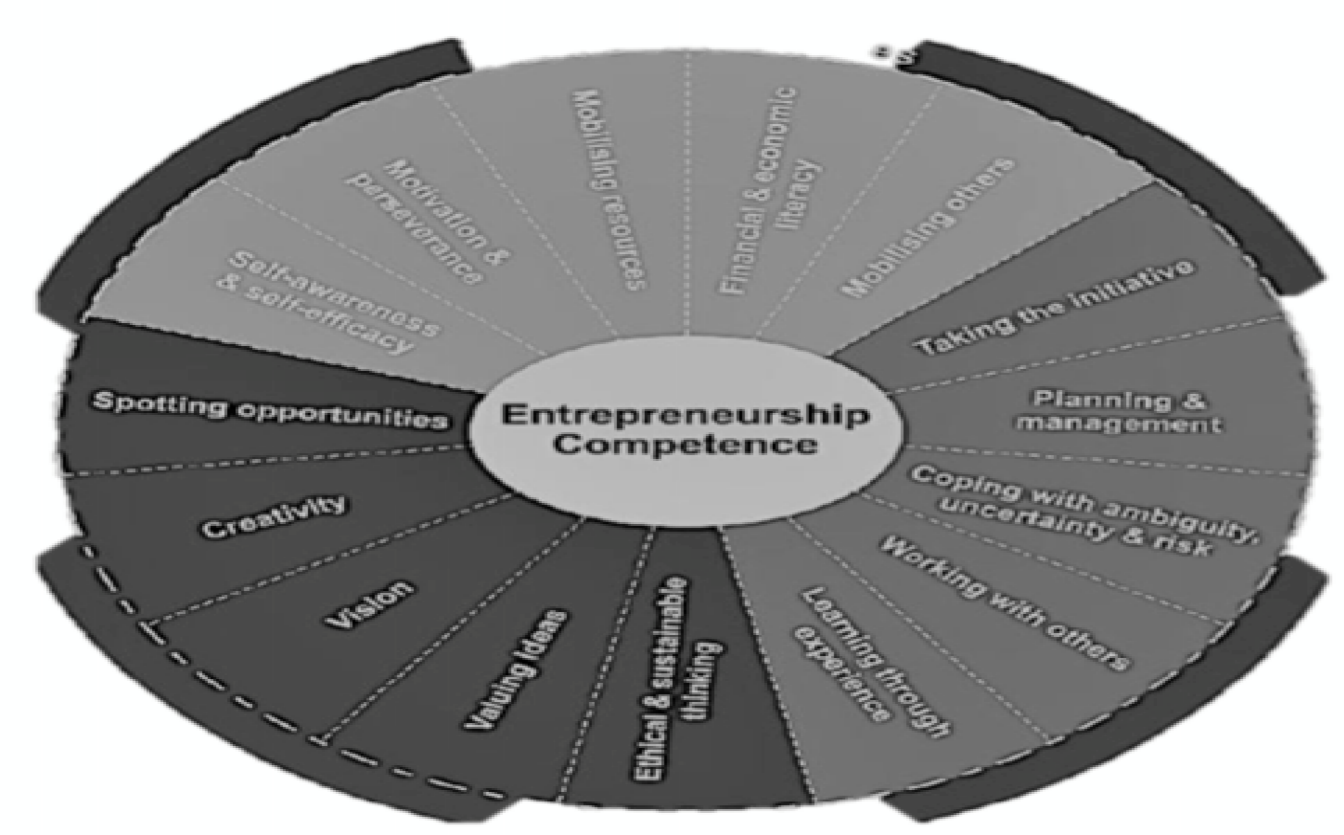

Fig. 2 showed entrepreneurship competence framework

Source: (Nwachukwu,Chladkova \& Zufan, 2017).

\subsection{Entrepreneurial Competencies Circle}

Generic entrepreneur competency circle was developed with the goal of identifying potentially successful 1 entrepreneurs and was developed by Mansfield et al (1996). This circle includes seven clusters which are: individual maturity, persuasion, directing and controlling, achievement, orientation to others, further competencies, as well as thinking and problem solving.

\subsection{Link between Strategic Management And Entrepreneurship}

Strategic management and entrepreneurship have a lot in common which points on the exploitation of opportunity and adaptability to change. However, two school of thoughts in the past opined the independent of one another until recently when scholars have advocated for the integration of the two. Integration of the two fields comes from the fact that strategic management needs to utilize resources for the exploitation of opportunities in conditions that are uncertain and entrepreneurship requires a strategic viewpoint in the preparation and taking of actions (10). The important objective of entrepreneurship is the recognition and utilization of opportunities, whereas the focus of strategic management is the process in which identified opportunities are changed into competitive advantages that are sustainable.

Creation of values is a major deliverable of both strategic management and entrepreneurship are (10). Nevertheless, the two can generate value independently, but this value is increased when the two are integrated. A strategic entrepreneurial behavior aid creation of value for an organization. There are six main domains where strategic management and entrepreneurship intersect: innovations, internationalizations, growth, and network, learning in the organization, top governance and management (10). 


\subsection{Problems of entrepreneurial development in Nigeria}

i. Lack of effective policy at the National Level: Though government of Nigeria is fully aware about the importance of entrepreneurial development, yet we do not have a national policy on entrepreneurship. It is expected that the government will formulate and enforce a policy aimed at promoting balanced regional development of various areas through promotion of entrepreneur.

ii. Poor Response of financial institution: entrepreneurs are not able to offer collateral security for the grant of loans. Banks are not prepared to play with the public money and hence they impose various conditions for the grant of loans those entrepreneurs who fail to comply with the conditions are not able to get loan and hence dream of setting up their own enterprises is shattered. Helpful attitude of lending institutions will go a long way in stimulating entrepreneurial climate.

iii. Inaccessible market: The majority of our people don't have access to markets, and in order for them to stand the requirements of the markets. So, this is one area where we are lacking. For instance, if you want to have access to the U.S market, you must know of the regulations, what it takes and all those things until we are able to create that very well and let people understand it, and produce to be able to meet the needs of the market, then will not be enabled to move forward.

iv. Lack of infrastructure: Depilated and non-provision of basic infrastructure by government of developing countries to drive innovation and economic growth is a challenge for entrepreneurship. This is basically (true) in all developing countries, but more so in Nigeria. Thirty percent of them not being competitive is based on infrastructure.

v. Unstable political system: the constant change in government causes uncertainty and increases the risk associated with investments (19).

2.6 Measures of entrepreneurial competency

New ventures are usually private organizations with no obligation to disclose competency information; therefore, traditional measures of financial competency are often unavailable or business owners are unwilling to share this information with outsiders. Thus, the use of multiple indicators to gauge competency is recommended. Inherent challenges in entrepreneurial research has identified three of the most common approaches to estimating entrepreneurial competency when only self-reported data is available; they are: (1) measuring firm performance in broad categories; (2) using measures of firm performance in relation to competitors; and (3) measures of other satisfaction with the firm's performance.

Throughout the literature, entrepreneurial firm performance is measured both objectively and subjectively. Objective measurement is typically examined by analyzing hard numbers or financial measures, where subjective performance is assessed more in terms of personal beliefs or views (5). Subjective measures are often self-report measures at the firm and/individual levels of analysis, such as the entrepreneurs' perspective on financial (example, growth, profitability) and non-financial (example, job satisfaction, product quality) dimension.

\subsection{Theoretical framework}

Schumpeter's theory propounded by Schumpeter's (1964)

This theory states that a vibrant profitable economy encourages people to venture into entrepreneurship while any action tending to squeeze profit such as increased bargaining power of trade unions, progressive income and corporate taxes, etc., will discourage enterprise. Schumpeter uses the concept of "social climate" to describe the whole lot of social, political and socio psychological environment within which the entrepreneur operates namely: educational system, social values, class structure, reward system etc. (Higgins, 1968)

\section{Management skills theory}

(19) Argues that management skill theory focuses on management school perspective that pointed on managerial skills which enable a person to exploits economic opportunities in the environment and obtain economic gain. This theory deals with technical aspect of management and believes that entrepreneurship can be developed and trained. Entrepreneurship educators and professionals have evolved beyond the myth that entrepreneurs are born, not made. Therefore, entrepreneurship educators have been challenged with the task of designing effective learning opportunities for potential entrepreneurs.

\section{Human capital theory}

Researchers have embraced human capital theory when using non-psychological factors to build models predicting entrepreneurial competency. (19) Economists have naturally addressed tangible, non-psychological factors such as physical capital, natural resources, and labor Attributes of human capital such as education, experience, knowledge and skills are argued throughout the literature as critical resources for entrepreneurial competency. The human capital - entrepreneurial success relationship has been well established and provides several arguments for 
how human capital can increase an owner's ability to be successful. For example, researchers contend that human capital plays a large role in entrepreneurial competency due to the constantly changing knowledge - intense occupation and work environment.

This study adopted Management skills theory because it believe on managerial skills which enable a person to exploits economic opportunities in the environment and obtain economic gain. This theory deals with technical aspect of management and believes that entrepreneurship can be developed and trained (9).

\section{Empirical Review}

(14) studied impact of women entrepreneurs as small-medium enterprise (SME) operators and their roles in socioeconomic development in Ota, Ogun State Nigeria, using simple frequency tables and regression analysis. Primary source of data was employed. The study made use of expo-factor research design. The results revealed that the extent to which the variance in poverty level can be explained by the activities of women entrepreneurs is $32.3 \%$ i.e. $(\mathrm{R} 2=.323), \mathrm{F}=16.790$, and $\mathrm{p} \leq 0.001$. This showed that the activities of women entrepreneurs have a significant effect on poverty level in Ota Ogun State Nigeria.

Nevertheless, the paper also discovered that a lot of women are uneducated; as far as business technicalities are concerned. The study recommended that State Government should encourage women in entrepreneurial activities and provide sound conducive business environment for women through provision of infrastructural facilities such as power supply.

(Wagner, 2003) conducted a study on impact of changes on entrepreneurial learning approaches that influence the improvement of entrepreneurs' capabilities, using Analysis of Variance (ANOVA). The study adopted survey research design. Data was sourced from primary source. The study revealed that entrepreneurial learning plays an important role in enhancing entrepreneurs' capabilities, with increasing research attention given to entrepreneurs' capabilities. He recommended that there is need to explore the building mechanism which has continued to escalate. In a study conducted by (Bahadori, 2012) to examine the effect of emotional intelligence on entrepreneurial behavior in organizations, using correlational analysis. A sample of 107 managers from a medical science university in Iran participated in the main study. Data was soured from primary source. Findings showed that all four dimensions of emotional intelligence have positive effect on entrepreneurial behavior. All the constructs were assessed with self-report measures based on multi-item scale and all responses to items were made on 5 points Likert scales for strongly disagree (1) to strongly agree (5). The self-report Wong and Law (2002) emotional intelligence scale comprising 16 items organized into four dimensions, was used. Findings showed that there isn't any difference between man and woman's entrepreneurial behavior $(P=0.128)$. Also, the test showed that entrepreneurial behavior differences among managers' university degrees are not significant $(\mathrm{P}=0.21)$. In keeping with recent studies (Zampetakis \& Kafetsios, 2010), the (Bahadori, 2012) study found regulation of emotion $(\mathrm{r}=$ $0.53, \mathrm{p}<0.01)$, as one of the dimensions of emotional intelligence positively related to entrepreneurial behavior. In addition, they found that use of emotion related to managers' entrepreneurial behavior $(\mathrm{r}=0.42, \mathrm{P}<0.01)$.

In an empirical study by (Kamalian et al. 2011), they studied the relations between employee's emotional intelligence with the route of their entrepreneurial orientation, using regression analysis. The target universe study was the state bank employees of Aghghala city consisting of 85 employees, though 75 questionnaires were returned completed. The data was sourced from primary source. The Goleman's questionnaire containing 5 dimensions was used. According to results obtained through regression analysis, the adjusted correlation between these two variables was $0 / 365$ and it indicated that $36 / 5$ percent of changes in entrepreneurial orientation result from emotional intelligence. So, they contended that people who had high emotional intelligence actually were capable of understanding their own feelings and others, they were also capable of analyzing and managing them, they also had high competence in recognizing opportunities precisely in doing activities uniquely and in risk-taking. Their correlation was corroborated through researches that had been conducted by (Zampetakis \& Colleagues 2009).

\section{Methodology}

This study made use of survey research design. The population consists of forty (40) managers of small and medium sized enterprises operating in Abuja Nigeria. Simple random sampling techniques was employed. The study made use of primary source of data through distribution of questionnaire, using a five-point likert scale questionnaire. Out of the forty (40) questionnaire, only thirty- six were returned and analyzed with the help of computer-based Statistical Package for Social Sciences (SPSS 20.1), using Pearson Product Moment Correlation to test hypotheses. 
Model Specification

The model is stated as:

$$
\begin{aligned}
& \mathrm{SM}=\mathrm{f}(\mathrm{CA}, \mathrm{DEC}, \mathrm{AEC}) \text {--------- }(1) \\
& \text { Where } \\
& \mathrm{SM}=\text { Strategic Management } \\
& \mathrm{CA}=\text { Competitive Advantage } \\
& \mathrm{DEC}=\text { Development of Entrepreneurial } \\
& \quad \text { Competencies } \\
& \mathrm{AEC}=\text { Advancement of Entrepreneurial } \\
& \quad \text { Competencies } \\
& \mathrm{SM}=\mathrm{b}_{0}+\mathrm{b}_{1} \mathrm{CA}+\mathrm{b}_{2} \mathrm{DEC}+\mathrm{b}_{3} \mathrm{AEC}+\mathrm{e}------(2) \\
& \text { Where } \mathrm{e}=\text { the Stochastic Term } \\
& \text { A priori Expectation is a }>0
\end{aligned}
$$

\section{Results and Discussion}

Hypothesis One: Strategic management does not significantly enhance competitive advantage in Nigeria.

\section{TABLE 1: TEST OF HYPOTHESIS ONE}

\begin{tabular}{llrr}
\hline \multicolumn{3}{c}{ Correlations } \\
\hline Strategic Mgt & Competitive Adv. \\
\multicolumn{4}{c}{} \\
Strategic Mgt Pearson Cor. 1.400 & $.817^{* *}$ \\
& Sig. (2-tailed) &. & 000 \\
\multicolumn{4}{c}{} \\
Competitive & 32 & 32 \\
Adv. Pearson Cor. & .817 & 1.400 \\
& Sig. (2-tailed) & 000 &. \\
& $\mathrm{~N}$ & 32 & 32 \\
\hline
\end{tabular}

**Correlation is significant at the 0.05 level (2-tailed

Source: Researcher's computation, 2019

Result of Pearson Correlation showed a positive correlation between Strategic management and competitive advantage with a correlation coefficient of 0.817 ( ). This relationship showed that strategic management it leads to an increase in competitive advantage in Nigeria by $81.7 \%$. This positive relationship is statistically significant $(p<0.05)$ and in consonant with a priori expectation. Therefore, we reject the null hypothesis, that is, our estimate is statistically significant. This means that Strategic management significantly enhance competitive advantage in Nigeria.

Hypothesis two: There is no significant relationship between strategic management and development of entrepreneurial competencies in Nigeria.

\section{TABLE 2: TEST OF HYPOTHESIS TWO}

\section{Correlations}

$$
\text { Strategic Mgt. Dev. Ent.Com. }
$$

\begin{tabular}{ccc} 
Strategic Mgt Pearson Cor. & 1.175 & $.710^{* *}$ \\
Sig. (2-tailed) &. & .000 \\
N & 29 & 29 \\
Dev. Ent.Com. Pearson Cor. & .710 & 1.175 \\
Sig. (2-tailed) & .000 &. \\
N & 29 & 29 \\
\hline
\end{tabular}

**Correlation is significant at the 0.05 level (2-tailed

Source: Researcher's computation, 2019 
Result of Pearson Correlation showed a positive correlation between strategic management and development of entrepreneurial competencies with a correlation coefficient of 0.710 . This relationship showed that when there is an increase of strategic management practices it leads to an increase in development of entrepreneurial competencies in Nigeria by $71.0 \%$. This positive relationship is statistically significant $(p<0.05)$ and in consonant with a priori expectation. Therefore, we reject the null hypothesis, that is, our estimate is statistically significant. This means that there is significant relationship between strategic management and development of entrepreneurial competencies in Nigeria.

Hypothesis THREE: Strategic management does not significantly enhance advancement of entrepreneurial competencies in Organization

\section{TABLE 3: TEST OF HYPOTHESIS THREE}

\begin{tabular}{ccc}
\hline \multicolumn{3}{c}{ Correlations } \\
\hline \\
Strategic Mgt. Adv. Ent.C
\end{tabular}

**Correlation is significant at the 0.05 level (2-tailed

Source: Researcher's computation, 2019

Result of Pearson Correlation showed a positive correlation between strategic management and advancement of entrepreneurial competencies with a correlation coefficient of 0.705 . This relationship showed that the implementation of strategic management leads to advancement of entrepreneurial competencies by $70.5 \%$. This positive relationship is statistically significant $(p<0.05)$ and in consonant with a priori expectation. Therefore, we reject the null hypothesis, that is, our estimate is statistically significant. This means that strategic management significantly enhance advancement of entrepreneurial competencies in Organizations.

\section{Conclusion and recommendations}

This study examined effect of strategic management on the development of entrepreneurial competency in Nigeria with key emphasis on the outcome of strategic management on competitive advantage, development of entrepreneurial competencies and advancement of entrepreneurial competencies in Organizations. A proper aligned strategic management of an organization can result to positive advancement of entrepreneurial competencies if well developed and implemented. Training centered on acquisition of entrepreneurial competencies is a key direction for Organizations to achieve it strategic goals.

The study therefore made the following recommendations:

1. Organizations should invest in training and retraining of their employees, as the human resource is an important internal strength of every organization, and are therefore a source of competitive advantage for every firm.

2. There should be effective policies governing strategic management processes in every organizations in order to enhance the level of competitive advantage.

3. Organizations should involve professionals in their strategic management processes to increase the level of development and advancement of entrepreneurial competencies in Organizations.

Areas for further research

Further research could be carried out on impact of strategic management on entrepreneurial performance in other countries to substantiate earlier studies that did not support effects of strategic management on the development of entrepreneurial competency in Nigeria.

\section{References}

\section{Journal Papers}

[1] Adebimpe A(2011) Assessing Nigerian Female Entrepreneur's Access To Finance For Business Start-Up And Growth, African Journal Of Business Management Vol. 5(13), Pp. 5348-5355. 
[2] Adeyemi, S. L. (2007) Nigerian Women Entrepreneurs and Their Personality Traits: Center Point Journal of Intellectual, Scientific And Cultural Interests, University Of Ilorin, Humanities Edition, Volume7 No 2, May, 1997 Pp. 179-188

[3] Ahmad, N., Ramayah, T., Wilson, C., \& Kummerow, L. (2010). Is Entrepreneurial Competency and Business Success Relationship Contingent Upon Business Environment? A Study of Malaysian Smes. International Journal of Entrepreneurial Behavior \& Research, 16(3), 182-203.

[4] Baba G.K. (2013) The Challenges of Entrepreneurship Development in Nigeria And Way Forward. Journal of Business and Organizational Development Volume 5, Number 1, 2013 Department of Business Administration and Management Studies. The Federal Polytechnic, Damaturu, Yobe State.

[5] Buttner, E. Holly \& Rosen, B. (2008) Perception of The Characteristics Of Men, Women And Successful Entrepreneurs. Journal of Business

[6] Brophy, M., \& Kiely, T. (2002). Competencies: A New Sector. Journal of European Industrial Training, 26(2/3/4), 165-176.

[7] Hisrich, Robert D (2006) The Women Entrepreneur: A Comparative Analysis. Leadership and Organization Development Journal. 7 (2): 8-16

[9] Jimah S. M Unuigbokhai, O. \& Jimah, K. (2015) Refocusing Education System Towards Enterpreneurship Development in Nigeria: A Tool for Poverty Eradication, Book Of Proceedings - Academic Conference Of Cambridge Publications \& Research International On Sub-Sahara African Potentials In The New Millennium Vol. 3 No.2.

[10] Kraus, S. \& Kauranen, I. (2009). Strategic Management and Entrepreneurship: Friends or Foes? International Journal of Business Science and Applies Management, 4(1).

[11], B., Kourosh, P., Mehdi, A., \& Saber, K. (2015). Investigating the Effect of Entrepreneurial Competencies on Business Performance Among Early Stage Entrepreneurs Global Entrepreneurship Monitor (Gem 2010 Survey Data. Journal of Global Entrepreneurship Research, 5(18), 1-12.

[12] Nieder, L. (2009). A Preliminary Investigation of Female Entrepreneurs in Florida. Journal of Small Busines Management, 25 (3): 22-29

[13] (2014). Nigeria Business Environment: Issue Challenges and Prospects. International Journal of Academic Research in Business and Social Sciences, 4(4), 132-138.

[14] Oluwole I. And Dominic A. (2014) Women Entrepreneurs as Small-Medium Enterprise (SME) Operators and Their Roles in Socio-Economic Development In Ota, Nigeria. International Journal of Economics, Business and Finance Vol. 2, No. 1, January 2014, Pp: 1 - 10.

[15] Sozuer, A., Altuntas, G. \& Semercioz, F. (2017). International Entrepreneurship of Small Firms and Their Export Market Performance. European Journal of International Management, 11(3), 365-382.

[[16] Zali, Mr, Bastian, B1, \& Qureshi, S (2013). Promoting Innovation in The Mena Region: The Role of Social Norms and Individual Factors in Entrepreneurial Networks. International Journal of Business and Globalisation, $11(4), 413-426$

\section{Books}

[17] Almeida, F. \& Buzady, Z (2019). Assessment of Entrepreneurship Competencies Through the Use of Fligby. Digital Education Review.

[18] Hitt, M., Ireland, R. \& Hoskisson, R. (2012). Strategic Management Cases: Competitiveness and Globalization. South-Western Pub.

[19] Mclaughlin, E. B. (2012) An Emotional Business: The Role of Emotional Intelligence in Entrepreneurial 
Success

[20] Ismail, T (2012). The Development 0f Entrepreneurial Social Competence and Business Network to Improve Competitive Advantage

[21] Business Performance of Small Medium Sized Enterprises: A Case Study of Batik Industry in Indonesia. Procedia-Social and Behavioral Sciences, 65, 46-51.

[22] Mansfield, R. S. (1996). Building Competency Models: Approaches for HR Professionals. Human Resource Management, 35(1), 7-18.

[23] Mojab, F, Zaefarian, R, \& Azizi, Ahd (2011). Applying Competency Based Approach for Entrepreneurship Education. Procedia-Social and Behavioral Sciences, 12, 436-447.

[24] Nwachukwu, C., Chladkova, H. \& Zufan, P. (2017). The Relationship Between Entrepreneurial Orientation, Entrepreneurial Competencies, Entrepreneurial Leadership and Firm Performance: A Proposed Model. Business Trends, 7(1), 3-16.

[25] Saijilan, S. \& Tehseen, S. (2015). Cultural Orientations, Entrepreneurial Competencies and SMEs Business Success: The Contingent Role of Environmental Turbulence and Network Competence. Rev. Integr. Bus. Econ. Res, 4(2), 20-35.

[26] Sammut-Bonnici, T. (2015). Strategic Management, In Wiley Encyclopedia Management. John Wiley \& Sons.

\section{Proceedings Papers}

[27] Krasniqi, E. \& Kume, A. (2013). Entrepreneurship and Strategic Management In Emerging Economies: Kosovo's Perspectives. Annales Universitatis Apulensis Series economic, 15(1), 267-279. 